\title{
ESTUDIOS PARA LA PAZ, \\ LA INTERCULTURALIDAD \\ Y LA DEMOCRACIA
}

Eduardo Andrés Sandoval Forero esaforero2002@yahoo.com

\section{RESUMEN}

El texto presenta un somero panorama de la complejidad de los conflictos y violencias que se presentan en el mundo, en América Latina y en particular en México. A partir de los planteamientos de los estudios para la paz, describe la violencia estructural sistémica, la violencia directa, la violencia cultural y simbólica existentes en nuestras sociedades. Enuncia las tipologías de paz existentes en el presente, para luego entrelazar la interculturalidad y la democracia en su dimensión investigativa y educativa en los estudios de posgrado cuyo objetivo es formar investigadores en el conocimiento teórico, analítico y metodológico de nuestras realidades violentas y pacíficas. Se propone para América Latina, desarrollar la perspectiva teórica de la Paz Integral, activa, noviolenta y duradera, es decir una paz sustentable, a partir de un re-enfoque que tenga como base, por un lado el conocimiento de nuestras realidades, y por otro, referentes hipotéticos de las teorías del pensamiento crítico latinoamericano en cualquiera de sus expresiones.

Palabras clave: paz integral, interculturalidad, democracia, noviolencias.

\section{Abstrac:}

The text describes a shallow outlook about the complexity of the conflicts and the violence that are shown on the world, on Latin America and in particular, on Mexico. From the establishment of the designs for peace, describes the structural systematic violence, direct violence, cultural and symbolic violence, 
in being in our societies. It enunciates the kinds of peace in existence in the present, intended to then entwine interculturality and democracy in their investigative and educative dimension in the post grade studies, whose objective is to form investigators on the theoretical, analytic and methodological knowledge about our peaceable and violent realities. It is proposed for Latin America to develop the theoretic perspective of the Integral, active, nonviolent and lasting Peace, that is a sustainable peace, from a re-focus on the basis, on one side of our realities, and on the other, hypothetical relating to theories of critical latinamerican thinking in any of its expressions.

Key words: integral peace, interculturality, democracy, nonviolence

\section{CONTEXTO DE VIOLENCIAS Y PACES}

a historia de la humanidad está conformada por una serie de acontecimientos que han marcado la vida económica, política, social, cultural y educativa de los pueblos del mundo con signos de convivencias pacíficas y también de violencias. Las dinámicas bélicas han dejado millones de pérdidas humanas, destrucción material y un profundo dolor en la humanidad. Basta recordar los millones de personas civiles asesinadas en los holocaustos de la primera y segunda guerra mundiales. No menores fueron las acciones bélicas de las famosas cruzadas que devastaron poblaciones enteras por pertenecer a otros credos religiosos. En tiempos más recientes la guerra contra el terrorismo, lanzada por la administración Busch después de los ataques terroristas del 11 de septiembre de 2001 realizados por al-Qaeda, han servido de pretexto para invadir, y bombardear indiscriminadamente ciudades y pueblos de países considerados "ejes del demonio".

En América Latina y en buena parte del mundo las relaciones políticas, sociales, económicas y militares han sido impuestas de manera activa y directa por los distintos gobiernos de la administración estadounidense. La intervención política y militar ha sido directa en países como Granada, Panamá, y Haití. Las bases militares en el subcontinente se amplían y el pretexto de la lucha contra el narcotráfico de drogas ilícitas les auto adjudica la militarización e intervención directa en los países involucrados, desintegrando comunidades y extensiones considerables del medio ambiente afectadas por las fumigaciones aéreas. Esta lucha contra el narcotráfico, y no por la prevención y contra el consumo de drogas ilícitas, se acompaña del tráfico más desproporcionado de armas jamás vivido en la historia de nuestros países. También se acompaña de la expropiación de territorios, de desplazamiento de población, y de la explotación directa de los minerales por parte de compañías trasnacionales que se aprestan a contribuir al desarrollo de buena voluntad. Toda esta compleja industria del negocio de la guerra y el saqueo, es una de las lacras que socavan cualquier condición humana.

De acuerdo al Mapa del Hambre divulgado por el Programa Mundial de Alimentos (PMA) de la ONU en 2011, cerca de mil millones de personas padecen por alimentos, es decir que una de cada seis personas está desnutrida, viviendo en condiciones infrahumanas y en inanición por no tener alimentos. Esta violencia emanada de las estructuras sociales y económicas en el mundo, impide que todos los habitantes tengan lo básico en alimentación, salud, vivienda y educación para tener una vida activa y digna. Lo lamentable, lo irracional, lo inaudito del absurdo del poder político y económico, es que millones de toneladas de alimentos son tiradas diariamente por falta de compradores, y las cantidades estratosféricas de la riqueza y el dinero se emplean en la ciencia y la tecnología para el desarrollo de la industria de la guerra. En los mismos países llamados pobres o subdesarrollados, en muchos de ellos los presupuestos de guerra son mayores a los de educación o salud. En este mapa del hambre que les menciono, México se encuentra entre los países que tienen $5 \%$ de su población desnutrida.

Una mirada panorámica de América Latina y en particular de México en el siglo XXI, nos exhibe inseguridad, violencias, corrupción, exclusión, injusticias, abusos de autoridad, violación de mujeres, pederastia, consumo de drogas psicotrópicas, asaltos, robo de autos, de casas habitación, tráfico de armas, personas y drogas, saqueo de recursos públicos, compra de votos, acoso sexual, enfrentamientos armados entre delincuentes organizados, abusos de autoridad, muertes colaterales, secuestros, torturados, desaparecidos, agresión escolar, consumismo, estrés, pobreza, pueblos desolados, desplazamientos forzados, destrucción del medio ambiente para el enriquecimientos de unos cuantos; son entre otras muchas realidades, marcas contextuales del deterioro social, económico, político y moral en el que hoy estamos inmersos los mexicanos.

La desintegración del tejido social, el dolor de los deudos, los más de 50 mil muertos, los miles de niños sin padres, el desamparo de los 120 mil desplazados de guerra, los 10 mil desaparecidos contabilizados en la administración actual de México (2006-2011), es sin duda una de las expresiones más de la situación de una parte del país, el México violento, intolerante, y destructivo, que lo tiene sangrando y en desintegración por tantas violencias que se nutren de una población mayoritaria que se debate en una 
lacerante miseria, sin futuro, y sin esperanzas reales de empleo y de un porvenir digno para todo ciudadano que habita la geografía nacional.

Estas violencias sistémicas y de la delincuencia organizada (oficial y no oficial), la podemos comprender al revisar la clasificación que presenta el Índice Global de Paz, del Instituto para la Economía y la Paz, donde México se ubica en el lugar 121 entre 153 países. El índice registra 23 indicadores, dentro de los cuales los más significativos del país en términos negativos tienen que ver con los niveles de violencia, los crímenes, la cantidad de homicidios por cada cien mil personas, el acceso a las armas, la violación a los derechos humanos, y la percepción que la sociedad asume frente al crimen. Este índice además de evaluar presencia y ausencia de violencia armada, laboral, escolar y familiar, mide condiciones de educación, bienestar social y material, gobierno, y aplicación o no de los derechos humanos.

Pero esa misma situación que es producto de las violencias estructurales internacional y nacional, de las violencias de la delincuencia organizada, de la violencia intrafamiliar, de las agresiones en la escuela, de la violencia cultural y psicológica cotidianas contra los indígenas, las mujeres, los niños, los discapacitados, los pobres, las minorías religiosas, los niños/as de la calle, y los indigentes, (vergüenzas todas nacionales), han generado diversos movimientos locales, estatales y nacionales que luchan contra estas violencias con miras a construir condiciones en México por la Paz con justicia y dignidad. Estas importantes experiencias pacíficas han dedicado tiempo a la reflexiones tales como: ¿por qué llegamos esta situación?, ¿cómo llegamos a esta barbarie?, ¿qué se pudo haber hecho para evitarlo?, ¿qué se puede hacer para corregir esos errores violentos e intolerantes con los que estamos aprendido a vivir? y ¿qué se puede hacer para restablecer el orden y sobre todo la paz entre los seres humanos?

En medio de esta crisis de paz que atraviesa todas las entidades de la república mexicana, emerge el otro México, el de la Paz, el de la tolerancia, el México de la convivencia, de la hospitalidad internacional, del reconocimiento y respeto a la diversidad étnica y cultural. Tenemos una larga trayectoria de paz que en este inicio de milenio pretende ser silenciada, una paz negativa, una paz imperfecta, pero con bases culturales, sociales y étnicas importantes para re-construir la sociedad y su tejido social en perspectiva de una paz integral. Es por ello que afloran pensamientos, iniciativas y prácticas que de manera ingeniosa buscan unir la palabra, el pensamiento y el sentir de hombres y mujeres que viven de manera inconforme, que cuestionan y se oponen a las violencias estructurales, económicas, físicas, culturales, étnicas y de género, así como a todas las injusticias que obstaculizan el vivir ciudadano en su cotidianidad del trabajo, estudio, empleo, diversión y convivencias sociales y familiares.

Gestos de protesta en contra de atentados; carteles que se levantan exigiendo el cumplimiento de los derechos fundamentales en todo ser vivo; organizaciones no gubernamentales que piden respeto a los derechos humanos; pueblos indígenas que exigen el cumplimiento de sus derechos colectivos; comunidades unidas en redes sociales que sin rostro y sin voz hacen circular a gritos cartas y denuncias implorando firmas de mentes conscientes para restarle a las injusticias por lo menos uno de entre tantos casos; y movimientos populares que dignifican la voluntad de lucha por la paz en las calles de los pueblos y ciudades, son sólo algunas de las tantas formas de resistencia pacífica que existen, en donde hombres y mujeres sin importar etnia, religión situación socioeconómica, condición política y nivel educativo, se unen para exigir a los gobiernos y a todos los actores violentos el cese a las violencias, a las injusticias y a las guerras. Con estas dinámicas sociales es posible una construcción de la paz en sentido amplio, porque implica que se concientice, se reconozca y se impulse a la paz desde las situaciones de conflicto. Además, construir la paz significa evitar o destruir todas las expresiones de violencia, la injusticia, el desencuentro, la miseria, la explotación, la incomunicación, la sumisión, las violencias de todo tipo y la desigualdad. Estas maneras de entender la paz se originan en el rechazo a la violencia física y a la inclusión de la población civil en la confrontación, garantizándole los derechos humanos, es decir en proyección de lo que los expertos denominan "paz positiva".

Cuando hablamos de paz nos estamos refiriendo también a las situaciones de conflicto. La paz se conforma por aquellos escenarios de no conflicto antagónico, de no exclusión, de no intolerancia, de no violencia, de no discriminación, y de no abusos. Con esto queremos decir que unas herramientas importantes para construir la paz son la negociación, el diálogo, la mediación, y la transformación pacífica de los conflictos a partir del diálogo, las normas, las leyes, los derechos humanos, y el reconocimiento de todas las diversidades culturales, étnicas, religiosas, políticas y sociales que permitan el fortalecimiento de las instituciones encargadas de garantizar y promover el bienestar social.

La paz no es solo la ausencia de la violencia física, es también la desaparición de la violencia cultural, social, económica, política, de género y de todas aquellas violencias que en lo simbólico agreden, denigran, excluyen y menosprecian a los otros, a los diferentes, a los extraños, o a los extranjeros. Es decir, la paz es la ausencia de la violencia de estructuras sociales y económicas, es el reconocimiento y valoración de la vida, la libertad, la justicia, los derechos humanos y las convivencias pacíficas de todos 
los diversos. A su vez es un proceso que no supone un rechazo al conflicto, sino una utilización razonable de él. En este sentido, la paz no es la usencia de la violencia, n el silenciamiento de las armas, es como lo dijo Martín Luther King: La verdadera paz no es simplemente la usencia de la tensión, sino la presencia de justicia (Diccionario Desearte Paz, 2009).

En el ámbito internacional, La Declaración Universal de los Derechos Humanos (ONU 1948), El Pacto Internacional de los Derechos Económicos Sociales y Culturales (ONU 1996), el pacto Internacional de Derechos Civiles y Políticos (ONU 1996), así como otros Tratados y Convenciones, consagran a la paz como un aspecto ineludible a tales derechos. En este sentido la Paz es un derecho individual y también colectivo, es un derecho que tienen las personas y también los colectivos sociales, los pueblos, las naciones, los Estado y todo el sistema internacional.

La paz, implica al igual que la violencia variados entornos de la vida del hombre, por ello referirnos solo a un tipo de paz o a un tipo de conflicto o de violencia, resulta poco cercano a la realidad, pues cada continente, país, región, estado, municipio o localidad, presenta contextos sociales y culturales históricos y del presente, que le impregna su condición particular de aplicarse, abordarse, entenderse y de enseñarse. No podemos por ejemplo pensar en tener en nuestro país las condiciones de paz que prevalecen en los países llamados del primer mundo o del mundo desarrollado, pues nuestras historias, realidades y condiciones distan mucho y no corresponden a ese mundo. Nuestras estructuras socioeconómicas, nuestras condiciones sociales, nuestras diversidades étnicas, culturales y religiosas, nuestras injusticias, en fin nuestra historia y nuestro presente, nos obligan a pensar y a construir la paz de acuerdo a nuestros propios contexto.

Por supuesto que tenemos que aprender de pensares y actuares de paz generados en todos los países y rincones del planeta, sobretodo de aquellas teorías y experiencias que sean susceptibles de ser funcionales a nuestro medio, pues en esta era de la globalización los conflictos y las violencias tienen repercusiones regionales e internacionales que obligan a que la paz, sustentada en la justicia social, el respeto a los derechos humanos, la interculturalidad y la democracia, sean un bien público y un derecho globales. Esta es una de las virtudes del nuevo paradigma de los Estudios para la Paz, que investiga todos aquellos fenómenos que determinan condiciones de conflicto y de violencias que afectan la convivencia pacífica en dimensiones micros como la familia, o macros como los conflictos entre países.

\section{Origen de los estudios para la paz}

Connotados investigadores de la paz (Galtung, Vicent Martínez, Vicenc Fisas Francisco Muñoz, y muchos otros), consideran que los estudios en este campo tienen sus orígenes formales después de la segunda guerra mundial (siglo XX), iniciando entonces una preocupación en torno a estudiar maneras distintas de generar paz desde disímiles puntos estratégicos como el social, cultural, económico, político y educativo. Entre los años 1934 y 1945 surge en los Estados Unidos las primeras organizaciones no gubernamentales (ONG), que después se encargarían de proliferar un nuevo pensamiento, nueva cultura de paz, y una nueva forma de vivir la vida a través de cátedras, seminarios y talleres de convivencia.

En los años 20, Wright y de Richardson, con sus análisis y Pitirim Sorokim, con sus teorías, clarificaban los motivos de la guerra. Considerándose éstos como los primeros antecedentes y padres fundadores de Estudios para la paz en su versión más genuina de "paz negativa". Sin embargo, es posible afirmar que los estudios para la paz empezaron como campo académico, hasta después de los años cuarenta y cincuenta del siglo pasado.

Finalizada la II Guerra Mundial se introduce por primera vez un programa de Estudios de la Paz en el Manchester College de Indiana. En los años 50 diversas universidades e institutos son fundados para investigar sobre la guerra, sus causas y consecuencias, desarrollando así los primeros estudios internacionales.

En 1959 Johan Galtung funda el Instituto Internacional de Investigación para la Paz, en Oslo, Noruega (Peace Research Institute de Oslo-PRIO-) plantea las definiciones de "paz positiva" y "violencia estructural", a partir de la perspectiva de comprender y analizar el mundo no sólo desde la violencia y la destrucción, sino también desde la justicia y la paz. En Galtung la paz se encuentra relacionada

con los conflictos y el desarrollo, aportando una amplia teoría sobre los conflictos, teniendo como preocupación central la transformación pacífica, noviolenta de los conflictos (Galtung, 1984).

Johan Galtung señala que existen diferentes tesis en los estudios para la paz, sin embargo, en una de esas tesis sostiene la necesidad de tomar en cuenta a los valores para poder hablar de paz. Para Galtung la ausencia de violencia directa, estructural, 
cultural y/o simbólica es lo que supone la realización de la supervivencia, el bienestar, la identidad y la libertad, es decir, la satisfacción de las necesidades básicas humanas. Esta primera división que se hace es la base sobre la que se cimentaron las teorías, filosofías y clasificaciones entorno a la paz que hasta la fecha continua en búsqueda de ejercer el respeto al otro para el bien común. Los estudios para la paz han sido abordados desde distintas y variadas áreas del conocimiento, es decir que son estudios multidisciplinarios, en los que podemos distinguir cuatro etapas generales (Martínez Guzmán 2009): La primera etapa de los estudios para la paz se desarrolla en el periodo correspondiente entre los años 30 y 60. Los estudios de la época se dedicaban al análisis de la paz desde una connotación negativa, es decir que el concepto de paz negativa alude a la ausencia de guerra, a la no existencia de la violencia física. Parte de los primeros pasos sobre este tema de investigación, fueron la creación de la revista Jornal of Conflict Resolution y del Center for Research on Conflict Resolution.

La segunda etapa de la investigación para la paz inicia con la constitución del Peace Research Institute de Oslo (PRIE), el International Peace Research Association (IPRA) en 1963 y la revista Jornal of Peace Research en 1964. La dinámica de investigación de estos centros, permite dar un giro en el concepto tradicional de paz, porque a partir de sus análisis visibilizan la paz positiva como alternativa a la violencia estructural, es decir a aquella violencia generada por las estructuras sociales que impiden la satisfacción de las necesidades básicas para todos los individuos. Esta definición de paz positiva, supone un nivel reducido de violencia directa y un nivel elevado de justicia, que intenta preservar la armonía social y la igualdad.

La tercera etapa de los estudios para la paz estuvo marcada por acontecimientos coyunturales de los años 80 , hechos que demandaron una mayor participación de los movimientos sociales con el fin de sumar actores en censura a la violencia directa, lo cual hace que a nivel general se diera mayor importancia a la solicitud de paz como ausencia de guerra.

La cuarta etapa inicia en la década de los 90, en este periodo la investigación para la paz adopta una perspectiva holística, integral y completa, que otorga gran importancia a la diversidad como medio para preservar la paz, a partir del aprovechamiento de las aportaciones de las otras culturas y del feminismo.

El siglo XXI plantea nuevos temas como conflicto global, derechos humanos, violencias trasnacionales, cooperación, militarismo, migración, narcotráfico, conflictos étnicos, violencia cultural, agresiones intraescolares, violencias online, diferencias económicas, exclusión, marginación, racismo, consumismo, violencias contra la naturaleza y el medio ambiente, empoderamiento, responsabilidad social, democracias, interculturalidad, globalización, tolerancia, y convivencias pacíficas, entre otros temas. Desde una visión antropológica y sociológica, podemos decir que se trata de realidades que atañen a la cultura de la violencia y también de entornos en que se construyen las culturas de paz.

Todas las formas de violencia son lacras que laceran a la humanidad, y todas ellas se relacionan directamente con el poder legal o ilegal en espacios amplios o con manifestaciones de micro-poder como la escuela o la familia. Una de estas violencias cotidianas no explicitas, es la conceptualizada y teorizada como violencia simbólica por el gran sociólogos contemporáneo Pierre Bourdieu, en sus explendidos textos titulados "Los modos de dominación" (Bourdieu, 1976), "Desconocimiento y violencia simbólica" (Bourdie, 1989), y La reproducción, donde diserta sobre los "Fundamentos de una teoría de la violencia simbólica". Esta violencia simbólica corresponde a un modelo de dominación que presenta mecanismos ocultos a lo que el sentido común no puede observar, y se conforma por la dupla dominación y dependencia. Esta violencia simbólica, invisible, que coexiste con las otras formas de violencia, es entendida como otra forma de dominación, y de acuerdo a Bourdie, supera la oposición entre las relaciones de sentido y las relaciones de fuerza, y se cumple y encubre a través de la comunicación.

Pensando nuestros contextos de violencias en México podemos discernir que la violencia simbólica no solo coexiste con las otras violencias, sino que también sirve para legitimarlas, para ocultar las relaciones de explotación, de dominación, de injusticias, de encubrimiento de unas estructuras socioeconómicas violentas soportadas por el Estado, la iglesia, la escuela, la familia, y por sistemas de comunicación que ocultan la realidad y falsean las realidades políticas, económicas, sociales, culturales, educativas y de violencia directa cotidianas.

\section{Educación intercultural para la Paz}

Regresando con Galtung, el tratamiento del conflicto por medios no violentos y si creativos, es crucial para lograr la paz y eso requiere profundizar en la cultura y en la estructura social, en llegar a dónde se origina el conflicto, y en buscar la mejor forma de prevenirlo y en su caso, de resolver los brotes de violencia o las secuelas del conflicto. Es por ello que el paradigma pretende no sólo el estudio del fenómeno sino también incidir significativamente en esas realidades, de tal manera que se produzcan tránsitos de una cultura de violencia a una cultura de paz, lo cual exige un proceso educativo en 
todos los niveles de la sociedad, desde la primaria hasta los niveles de posgrado.

Ante estas nuevas problemáticas de investigación y estas nuevas formas de hace investigación, surge la Educación para la Paz y la interculturalidad como un intento de querer contextualizar e integrar, de querer cambiar las conductas de la gente y de hacer realidad los derechos de los humanos, siempre de una forma no violenta y si tolerante. Un modelo de educación para la paz presupone no sólo informar sobre la amplia cosmovisión de la paz, sino que paralelamente exige un replanteamiento de propio proceso de enseñanza-aprendizaje acorde con los valores de paz (Jares, 1999: 120)

En un mundo dividido y sometido a cambios drásticos como al que nos enfrentamos día con día, todo ser humano al venir al mundo tiene el derecho a que se le eduque; después y en pago, tiene el deber de contribuir a la educación de los demás de manera formal o informal. Estas palabras entendidas como derecho y deber son vitales para forjar el cimiento de una sociedad de aprendizaje para la paz, la interculturalidad y la democracia.

La educación para la paz y la interculturalidad van más allá de la información de valores; tienen que ver directamente con la educación en valores, con la formación a partir de los valores y con la práctica de ciertos valores para lograr el cambio de actitud en los humanos. Es un proceso que debe estar presente en el desarrollo de la personalidad. Como proceso, debe ser continuo y permanente para enseñar a los alumnos a aprender a vivir en la noviolencia y a que depositen su confianza en la justicia, el respeto, la tolerancia y la felicidad.

No quiero mi casa amurallada por todos lados, ni mis ventanas cerradas. Yo quiero que las culturas de todo el mundo soplen sobre mi hogar tan libremente como sea posible, pero me niego a ser barrido por ninguna de ellas.

Palabras pronunciadas por Mahatma Gandhi, que además de su elocuente retórica, en su contenido reconoce plenamente la diversidad cultural y sus grandes aportes para la humanidad, al mismo tiempo que se opone firmemente a la uniformidad cultural, a la imposición de una sola cultura sobre todas las demás. Este sin duda debe ser uno de los principios de la educación intercultural para la paz.

Educativamente la educación para la paz y la interculturalidad, pretenden por medio del proceso de enseñanza - aprendizaje y el conocimiento, formar una cultura de paz que implique una ética personal y social fundamental para la convivencia basada en la libertad y en la igualdad sociocultural, inspirada en el respeto y reconocimiento de los derechos humanos, convenios internacionales, igualdad de trato y justicia. La educación para la paz fundamenta su carácter intercultural a nivel mundial con la meta de que todos los pueblos sin importar género, condiciones económica, etnia, o religión, opten por el desarme, por la noviolencia y por la transformación de conflictos pacíficamente para lograr entablar relaciones apacibles.

Algunas implicaciones de la educación para la paz son los valores, lo político y lo pedagógico (Jares, 1999):

a). Los Valores se consideran fundamentales en la educación para la paz. De la aplicación de ellos depende el éxito de educar con paz, por tanto, no pueden ser todos los valores, tampoco los que sean. Los valores que están implícitos son aquellos que circundan en la paz y los derechos humanos como la tolerancia, el respeto y la responsabilidad.

b). Lo Político en la educación para la paz busca transformar la dominación y el poder autoritario, por condiciones necesarias que favorezcan la justicia social, el pensamiento crítico, el ejercicio de la democracia directa, participativa o representativa, así como todas las prácticas comunitarias y colectivas.

c). Lo Pedagógico en los estudios para la paz consta de tres ámbitos: los fines (el por qué, la finalidad y los objetivos); los medios (el cómo, la metodología); y el curriculum (el qué: los contenidos y la estructura). Lo anterior con el objetivo de promover la paz y los derechos humanos.

\section{Algunas perspectivas teóricas para la Paz}

Varias son las corrientes teóricas que se vienen desarrollando en los estudios para la paz, las cuales podemos mencionar de manera rápida.

1.- Paz directa, estructural o cultural.- interpretada por Galtung como Paz Positiva y/o Paz Negativa. Paz positiva para Galtung es la paz auténtica, aquella que se opone no sólo a la guerra sino también a toda discriminación, violencia u opresión. Aquella que impide un desarrollo digno de las personas.

Paz negativa: este concepto de paz que sigue vigente en la actualidad, es el concepto tradicional occidental de no-agresión; de no conflictos. Esta paz es limitada esencialmente como concepto negativo, al ser definida como ausencia de 
conflicto bélico o como estado de no-guerra, sin tener en cuenta las otras violencias existentes.

2.- Aprender a hacer las paces.- Vicent Martínez Guzmán, fundador y exdirector de la Cátedra UNESCO de Filosofía para la Paz de la Universitat Jaume I. Propone una reconstrucción de las competencias humanas para hacer las paces y justificándose en las grandes diferencias que existen y la multiplicidad de formas en que los seres humanos interpretan, desarrollan y construyen las soluciones y/o negociaciones de los conflictos que se presentan. Vicent pretende mostrar que el hombre es generador de situaciones violentas, intolerantes y excluyentes; pero también puede llegar a ser protagonista de sentimientos de cariño, comprensión, ternura y cuidados. Propone desaprender las culturas de la violencia, prácticas filosóficas de educación para la paz, y la transformación d los conflictos y la educación en los sentimientos (Martínez, 2005). En palabras del filósofo: "En nuestra propuesta, la filosofía para hacer las paces será la reconstrucción de las competencias humanas para vivir en paz. (...) En este caso educarnos para la paz sería potenciar aquellos sentimientos que nos hacen competentes para construir nuestras relaciones por medios pacíficos" (Martínez, 2005: 145). En la definición de Vicent, "La filosofía para hacer las paces ha de ser una filosofía basada en la interculturalidad entendida como interpelación entre saberes y diálogo, más que choque de civilizaciones" (Martínez, 2005: 42)

3.- Paz Imperfecta.- Concepto propuesto por Francisco Muñoz del Instituto de la Paz y los Conflictos de la Universidad de Granada, quien argumenta la paz imperfecta como aquellas situaciones en las que se satisfacen las necesidades de los humanos, pero sigue presente la violencia en todas o al menos en una de las estructuras de carácter humano (familia, escuela, trabajo, relaciones sociales, cultura, economía, entre otras). “...podríamos agrupar bajo la denominación de paz imperfecta todas estas experiencias y espacios en los que los conflictos se regulan pacíficamente, es decir en los que las personas y/o grupos humanos optan por facilitar la satisfacción de las necesidades de los otros. La llamamos imperfecta porque, a pesar de gestionarse pacíficamente las controversias, convive con los conflictos y algunas formas de violencia". Entendemos entonces que el concepto de "paz imperfecta" alude a condiciones históricas y sociales que en su condición máxima de paz coexiste con conflictos y en algunos casos con violencias lo cual permite hablar de "paz estructural imperfecta" y de "violencia estructural imperfecta" (Muñoz, 2009), lo que implica que la paz es un proceso inacabado y permanente.

Nos hemos referido al nuevo paradigma de los estudios para la paz, nuevo para la investigación social, no porque haya empezado ayer. Como ya se dijo, estos estudios iniciaron más o menos en los años 40's después de la Segunda Guerra Mundial. Pero en términos de las ciencias sociales este es un paradigma nuevo, porque tiene como peculiaridad enseñar a analizar el mundo, la sociedad, las culturas, la política, y las violencias desde la perspectiva de paz y a reflexionar y pensar los conflictos como oportunidades de aprendizaje y enseñanza pacíficas.

Galtung y todos los investigadores de la paz, argumentan la necesidad de un "giro epistemológico" para comprender ésta otra perspectiva de conocer el mundo, las sociedades, las culturas, las vivencias, las violencias, los conflictos, y en general la realidad y la subjetividad en sus dimensiones teóricas y analíticas. Para ello, "no hay nada más práctico que contar con una buena teoría" (Galtung, 2003) que permita conocer las violencias, así como también la justicia y la paz.

Sin embargo, hablar de violencias y de paz en América Latina supone plantearse otros conflictos, otras necesidades, otros contextos y otras formas de ver, entender y vivir las violencias, las paces, y las diversidades, situaciones muy diferentes a las planteadas en el contexto europeo.

Las violencias estructurales, físicas, culturales, y simbólicas que padecemos en México, son violencias que se manifiestan directamente contra los indígenas, contra la mujer, contra los homosexuales y lesbianas, los discapacitados y migrantes, los menores de edad y ancianos, otras religiones y otros políticos, gente marginada que vive en las calles, ciertos extranjeros (xenofobia), y las agresiones culturales y físicas que se presenta dentro de las escuelas. Estos conflictos y demás violencias pueden ser abordados para su análisis bajo las perspectivas teóricas de la paz positiva, la paz negativa, hacer las paces y la paz imperfecta, pero necesitan fuente de análisis y argumentos y propuestas de solución desde el pensamiento y la praxis latinoamericanos y mexicanos.

Ante estas circunstancias específicas de Latinoamérica y de México en particular, los estudios para la paz, la interculturalidad y la democracia, posibilitan desarrollar la perspectiva teórica de la Paz Integral, activa, noviolenta y duradera, es decir una paz sustentable, a partir de un re-enfoque que tenga como base, por un lado el 
conocimiento de nuestras realidades, y por otro, referentes hipotéticos de las teorías del pensamiento crítico latinoamericano en cualquiera de sus expresiones.

Vale la pena acotar que la lucha por la paz integral no pretende arribar al modelo convencional de desarrollo capitalista, toda vez que este modelo se sustenta en la acumulación irracional de capital, para lo cual requiere de estructuras socioeconómicas violentas manifestadas entre otras realidades, en la explotación intensa de la mano de obra, de la exclusión, de la pobreza y la miseria de millones de seres humanos, situación que se acompaña de la destrucción irrazonable y violenta de la naturaleza y el medio ambiente en general.

Este desarrollo capitalista convencional conceptualizado como "mal desarrollo", no garantiza la satisfacción de las necesidades básicas como el bienestar, la libertad, la identidad y seguridad, analizadas desde lo Estatal-local, el ecosistema, y el sistema mundial (Tortosa, 2008). Otras son las alternativas que se proponen y se construyen en diferentes sectores, espacios y dimensiones, tales como "El buen desarrollo" (Acosta, 2000); El Decrecimiento (Serge Latouche, 2009); el "estar bien" o Allin Kay; el "vivir bien" o Suma Qamña; el "buen vivir" o Sumak Kawasay en lengua quechua (Acosta y otros, 2009) en sus reflexiones teóricas y políticas, así como en las consagraciones constitucionales de Ecuador y Bolivia; los "planes de vida" de los indígenas Nasa; la convivialidad en México; y las "Juntas de Buen Gobierno" en las autonomías zapatistas, son entre otras, expresiones del pensar y del actuar de otros mundos posibles, pacíficos y en armonía con la naturaleza.

Se plantea una paz integral porque no tiene que ser una paz solamente reducida a ciertos aspectos y ámbitos de la vida, sino que tiene que ser completa, de un todo y en todos los aspectos, pues de lo contrario hablaremos y tendremos una paz frágil, vulnerable, negativa. Esta paz integral está condicionada a que haya justicia, libertad, respeto a los derechos humanos, a los derechos colectivos de los pueblos indígenas, a la autonomía, interculturalidad, y democracias reales. Si alguno de estos aspectos no se hace presente, entonces no hay paz integral, y será una paz de baja intensidad, una paz excluyente sometida a constantes vaivenes, es decir una paz demasiado imperfecta con la potencialidad de generar situaciones de violencias de manera regular.

La paz integral estudia, analiza y caracteriza las condiciones de paz que tenemos a partir de los conceptos de paz activa, no violenta, lo que desde el pensamiento latinoamericano implica decolizarnos en el pensar y en la praxis de la paz, tanto en los estudios del pasado, como del aquí y del ahora, teniendo como referente analítico a la paz con base en la justicia social, la interculturalidad y la democracia.

La integralidad de la paz implica la superación de todas las violencias que hemos hablado, de las satisfacciones materiales y culturales de los pueblos, de las relaciones interculturales de igualdad, reconocimiento y pacíficas, de un Estado social de derecho, del ejercicio pleno y respetuoso de las democracias representativas, participativas, y directas, de la equidad de género, del respeto total a los derechos humanos, y del reconocimiento jurídico y real de los derechos colectivos de los pueblos indígenas. Seguro que todo ello es una gran utopía, pero la paz tiene utopías de la misma magnitud que las realidades pacíficas que la humanidad ha construido en el devenir de la historia. La paz integral se presenta como el antídoto de condiciones insostenibles para la paz, y los fundamentos teóricos que describen las condiciones de la paz imposible se encuentran en la persistencia de las violencias físicas y culturales que se anidan con la violencia estructural conformada por la pobreza, la marginación, la explotación y la exclusión social y educativa, es decir en condiciones determinadas por las violencias sistémicas. Caracterizar una situación de paz imposible significa que mientras no se revierta todo ese entorno de violencias, la paz integral se torna poco posible, y el deber del Estado y de sus instituciones como las universidades, es contribuir a transformar esas adversidades, por hacer posible las paces.

El plantear condiciones de paz imposible no implica negar los esfuerzos que hace el Estado por atender a la pobreza, por reconocer a la interculturalidad y abrir espacios educativos como semilleros de conocimientos para la convivencia pacífica, y en permitir a las instituciones de educación superior instrumentar planes y programas en perspectiva de interculturalidad para la paz y la democracia, así como modelos de organización académica diferente con grandes potencialidades tanto en términos de formación como en la pertinencia de incidir en la realidad.

\section{Democracia y Paz}

Los estudios para la paz integral incluyen el análisis de las democracias en América Latina, los cuales han sido restringidos en el debate y la praxis a la dimensión jurídica y política de los partidos políticos, del sistema electoral, y de todos los condicionantes propios de la formalidad instrumental e institucional como única forma de ejercicio del poder político, mientras que en contexto comunitarios y colectivos de campesinos e indígenas, existen dinámicas de democracia directa, participativa y de usos y costumbres, exhibiendo toda una gama de prácticas democráticas que bien vale la pena que sean analizadas para tratar de explicar las conductas manifestadas, los conflictos 
surgidos durante los procesos de democracia, y las diferentes formas de enfrentar los conflictos.

Múltiples son las definiciones conceptuales elaboradas sobre la democracia, las cuales se redefinen en el transcurrir de las transformaciones sociales, de los modelos de sociedad y del devenir histórico. Sin embargo, la dinámica democrática en las dos últimas décadas del siglo XX fue tan exitosa que las constituciones en América Latina incorporaron cambios significativos de reconocimiento a la diversidad étnica y cultural y a ciertos derechos de los pueblos indígenas.

Los países se han declarado multiculturales y se han pronunciado por el respecto al reconocimiento de los derechos humanos y colectivos de los pueblos indígenas. Sin duda ha sido un paso importante para la democracia, la que se acompaña de la promoción de la interculturalidad en el plano educativo, con la creación de universidades interculturales, cuyo proyecto apunta a las relaciones de reconocimiento, respeto e igualdad entre personas y grupos de culturas diferentes.

Los argumentos aquí expuestos manifiestan la persistencia por querer dignificar al hombre ante las injusticias que enfrenta día con día, y al mismo tiempo querer formarlo con las herramientas necesarias que le permitan ser consciente de la realidad para poder continuar con el quehacer del reconocimiento de los derechos del ser humano. Este paradigma en perspectiva de paz e interculturalidad, "rompe con todo el positivismo metodológico y teórico clásico y dominante; entonces al romper con eso tiene un primer elemento que no es disciplinar, sino que pertenece a diferentes áreas del conocimiento, es un paradigma multi-interdisciplinar, es un paradigma integral, es un paradigma que incluye todas las ciencias posibles duras y nobles".

\section{Reflexión final}

En síntesis, hacemos referencia a una paz integral intercultural que se propone afectar positivamente todos y cada uno de los aspectos de la vida personal, familiar, social, regional, nacional, continental y mundial. En lo particular, la educación intercultural para la paz, busca recuperar el valor de la humanidad a través de la educación para hacer frente a los retos del futuro desde el aprendizaje de una cultura universal. Pero debemos reconocer, que a pesar de que la educación pueda considerarse como el elemento más valioso para construir una cultura de paz, también, la educación necesita de nuevos aprendizajes innovadores que se abran a la problemática de mundo y preparen a las generaciones jóvenes para enfrentarlos de manera creativa y constructiva a las violencias, conflictos e intolerancias de hoy.

Pero para generar las condiciones para vivir en paz en el México del siglo XXI, se requiere de compromisos del Estado, de toda la sociedad, de los políticos, de los partidos, de las iglesias, de las instituciones del Estado, de la educación y en particular de las universidades. Nuestra tarea y compromisos son los de educar e investigar para la paz, en contribuir en la formación de una cultura de la tolerancia, del reconocimiento, de la convivencia pacífica de todas las culturas, las etnias, las religiones, las regiones, la políticas, los géneros y los todos. Para esta noble tarea tenemos el nuevo paradigma de los estudios para la paz con sus teorías, métodos, técnicas de investigación y análisis multivariados que otorgan los elementos necesarios para que los estudiantes adquieran los conocimientos básicos para realizar investigaciones sobre los conflictos, las violencias, las paces, la interculturalidad y la democracia a partir de actitudes y aptitudes pacíficas de ver el mundo, los grupos étnicos, y las otras culturas.

Este nuevo planteamiento de estudiar e investigar nuestras realidades es lo que nos tiene aquí reunidos para iniciar formalmente el programa de posgrado en estudios para la paz, la interculturalidad y la democracia, cuyo objetivo es formar investigadores de excelencia en el conocimiento teórico, analítico y metodológico de la paz, la interculturalidad y la democracia en contextos de violencia estructural, física, cultural y simbólica existentes en México y América Latina.

La UAIM es una institución que se propone contribuir al desarrollo de la sociedad a través de la educación intercultural, la cual es la base de principios relacionados con el paradigma de la paz en sus propósitos de la convivencia pacífica soportada en el reconocimiento de la diversidad cultural, el respeto y la interacción pacífica de todas las culturas. La realidad multicultural, multiétnica y multilingüe de México es una de las grandes riquezas históricas y presentes que requieren ser aquilatadas en sus dimensiones políticas, sociales, económicas y culturales con bases de justicia y democracia para poder construir un país con presente y futuro basado en el respeto y en el bienestar de toda su población.

La cultura entendida en sentido antropológico tiene que ver en sentido amplio con la forma de vida que tienen las naciones, los pueblos, las regiones, las localidades, las comunidades, las familias y las personas integrantes de esos colectivos, por lo que existen muchas maneras de la vida cotidiana que se relacionan con la condición social, económica, étnica, religiosa, política, lingüística, de género, sexo, edad, e incluso 
condición de salud como en el caso de los discapacitados. Contemplar esta realidad cultural diversa, nos induce a plantear que la interculturalidad atañe no solamente a las culturas de grupos étnicos (mestizos, afros, indígenas, gitanos, migrantes, etc.) sino también de manera más abarcativa de todas y todos lo que se diferencian de las demás formas de vivir, por lo que una de las políticas de la educación intercultural debe ser no solo el reconocer y respetar a todas las culturas diferentes, sino incidir en su inclusión, en su reconocimiento con empoderamiento pacífico.

En ese mismo entender antropológico, la interculturalidad alude a la relación entre el "nosotros" y el "otro" (o los "otros"), denotando una profunda tensión en esas relaciones entre culturas, lo cual ha sido motivo de interesantes discusiones desde hace unas tres décadas. Ese "nosotros" y esos "otros" culturales, interpela el sentido del ser de los científicos sociales, pues las fronteras del "nosotros" en muchos casos parecen diluirse en el entramado de las redes y relaciones entre culturas, que estrechan la relación con el "otro", y por ello, redimensionan nuestra cultura y nuestra identidad.

En este tenor, y respondiendo al compromiso social de la UAIM, institución intercultural del Estado de Sinaloa, iniciamos la Maestría y el Doctorado en Estudios Para la Paz, la Interculturalidad y la Democracia para contribuir desde la academia a formar investigadores comprometidos con la realidad social de nuestro país, apegados al paradigma de las investigaciones para la paz, a los postulados de la Cultura de Paz de la UNESCO, así como a todas las elaboraciones teóricas y experiencias prácticas existentes en América Latina y en México en particular.

Estimados estudiantes del posgrado, profesores, periodistas y público que nos acompaña; voy a terminar mi intervención con dos datos de gran trascendencia para la paz. Una es que la Asamblea General de las Naciones Unidas, proclamó en su resolución 36/67 de 1981, El Día Internacional de la Paz, el cual se celebra desde el año 2001, en el mes de septiembre el día 21, con el propósito de contribuir en esta fecha a fortalecer los ideales de la paz y la noviolencia. En este año 2011, el tema de esta celebración es "Paz y democracia: haz que tu voz se oiga".

Otra noticia importantes es que para llevar a cabo la comprensión, formación y aplicación de la educación para la paz, en varias partes del mundo se imparten posgrados en estudios sobre la Paz, los conflictos y el desarrollo, algunos auspiciados por la UNESCO, con estudiantes de diversos países y con catedráticos internacionales e interculturales que poseen tradiciones académicas diversas y ofrecen una formación interdisciplinar en todos los campos del saber.

Esto por supuesto es plausible, lo lamentable es saber que en Latinoamérica, donde tenemos presencia cotidiana de todos los tipos de violencia, y donde la diversidad étnica, cultural, religiosa y política afronta por una parte intolerancias, agresiones y violencias, y en otras circunstancias convivencias pacíficas, armónicas, de respeto, de apoyo mutuo y de solidaridad, tan solo existan dos maestrías en los estudios mencionados, y ningún doctorado para el año 2011.

Es por ello que el posgrado en Estudios para la Paz, la Interculturalidad y la Democracia que iniciamos hoy en esta Universidad, y en las condiciones de México que hemos esbozado, cumple un papel histórico, por ser la primera institución universitaria de nuestro país y de Latinoamérica que oferta un doctorado en este campo de estudios. Para llegar a este inicio se requiere de una administración de la UAIM con compromiso político con la educación intercultural, voluntad política, recursos económicos, infraestructura, sensibilidad por la problemática social de México, y una responsabilidad con la paz y la democracia en México.

Por fortuna cada día somos más conscientes de que vivimos en un mundo poco amable, rebozado de conflictos, agresiones y violencias que tienen múltiples formas, contenidos y manifestaciones, razón por la que el posgrado en los Estudios para la paz, la interculturalidad y la democracia de la UAIM, se propone formar investigadores del nivel que requiere el país, la universidad, la sociedad y la ciencia. Es decir que todas y todos Ustedes, maestrantes y doctorantes, son bienvenidos a contribuir con este compromiso histórico de la educación intercultural, de la paz, de la UAIM y de México en general.

Muchas gracias por su atención y reciban nuestra más sincera bienvenida pacífica a este programa de posgrado!

\section{REFERENCIAS BIBLIOGRÁFICAS}

- Acosta, Alberto, y otros (2000): El desarrollo en la globalización. El reto de América Latina. Quito, Nueva Sociedad

- Acosta Alberto, Edgardo Lander y Eduardo Gudynas (2009): El Buen Vivir una vía para el desarrollo. Quito, Abya - Yala. 
- Bourdieu, Pierre (1998) La reproducción, México: Ediciones Fontamara.

- Bourdieu, Pierre (1976). "Les modes de domination", en ARSS, n 8-9, junio, páginas 122-132)

(1989). "Desconocimiento y violencia simbólica", en La Nobleza de Estado. Grandes escuelas y espíritu de cuerpo". Les Editions de Minuit, Paris, 1989.

- Diccionario desearte paz, Centro Colombo Americano. Disponible en:http://www. deseartepaz.org/?cat=32. Fecha de consulta 20 julio de 2009.

- Galtung, Johan (2003) Trascender y transformar. Una introducción al trabajo de conflictos, México, Transcend - Quimera, introducción.

- Galtung, Johan (1984) iHay alternativas! 4 caminos hacia la paz y la seguridad, Madrid, Tecnos.

- Jares, Xesús R (1999). Educación para la Paz. España: Popular, S.A.

- Latouche, Serge (2009). La apuesta por el decrecimiento.¿Cómo salir del imaginario dominante? Barcelona, Icaria Antrazyt.

- Martínez Guzmán, Vicent (2009). Filosofía para hacer las paces. España: Icaria

- Muñoz, Francisco (2009), Paz Imperfecta. Disponible en:http://www.ugr. es/ fmunoz/documentos/Paz\%20imperfecta.html. Fecha de consulta 30/07/2009.

- Sandoval Forero, Eduardo A. (2001), "Ley para los indios: una Política de Paz Imposible en un Mundo donde no Caben más Mundos" en la revista Convergencia, Año 8, № 25,. Toluca: FCPyAP-UAEM.

- Tortosa, José María (2008A): “Maldesarrollo y desglobalización", Fundación Carolina, Universidad de Alicante, diciembre de 2008, disponible enhttp:// www.iudesp.ua.es/documentos/maldesarrolloDesglobal.pdf.Fecha de consulta $17 / 02 / 2011$.

\section{Eduardo Andrés Sandoval Forero}

Investigador-Profesor del Centro de Investigación y Estudios Avanzados de la Población de la UAEM.

Antropólogo (Escuela Nacional de Antropología e Historia) Maestro en Estudios Latinoamericanos (UAEM) Doctor en Sociología (Universidad Nacional Autónoma de México), Estancia posdoctoral en Diversidad cultural, Democracia y Paz (Instituto de la Paz y los Conflictos, Universidad de Granada, España).

Miembro del Sistema Nacional de Investigadores de México desde 1995 (nivel II). Profesor invitado de universidades de: Estados Unidos, América del Sur, España e Italia. Es profesor del curso Migración y codesarrollo, en la Cátedra UNESCO de Filosofía para la Paz, del posgrado de Estudios para la Paz y el Desarrollo, en la Universitat Jaume I de España de 2002 a la fecha.

Integrante del Grupo de investigación Internacional "Paz y regulación de conflictos", del Instituto de la Paz y los Conflictos de la Universidad de Granada y de la Junta de Andalucía.

Fundador y Coordinador Académico Honorario del Doctorado en Estudios para la Paz, la Interculturalidad y la Democracia de la Universidad Autónoma Indígena de México (UAIM). 